\title{
Development of a Renewable Hydrogen Economy - Optimization of Existing Technologies
}

\author{
Nelson A. Kelly, Thomas L. Gibson, Mei Cai, James A. Spearot \\ General Motors Research and Development Center \\ Warren, MI 48090-9055 USA \\ David B. Ouwerkerk \\ General Motors Advanced Technical Center \\ Torrance, CA 90505-5103 USA
}

\begin{abstract}
There is an increasing need for new and greater sources of energy for future global transportation applications. One recognized possibility for a renewable, clean source of transportation fuels is solar radiation collected and converted into useable forms of electrical and/or chemical (hydrogen) energy. This paper describes methods for utilizing and combining existing technologies into systems that optimize solar energy collection and conversion into useful transportation fuels. Photovoltaic (PV)-electrolysis (solar hydrogen) and PV-battery charging systems described in this paper overcome inefficiencies inherent in past concepts, where DC power from the PV system was first converted to AC current and then used to power electrical devices at the point of generation, or fed back to the grid to reduce electricity costs. These past, non-optimized concepts included efficiency losses in power conversion and unnecessary costs. These drawbacks can be avoided by capitalizing on the unique feature of solar photovoltaic devices that match their maximum power point to the operating point of an electrolyzer or a battery charger without intervening power transformers. This concept is illustrated for two systems designed, built, and tested by General Motors for fueling a fuel cell electric vehicle and charging an automotive propulsion battery. Based on this research, we propose a scenario in which individual home-owners, businesses, or sites at remote locations with no grid electricity, can capture solar energy, store it as hydrogen generated via water electrolysis, or as electrical energy used to charge storage batteries. Such a decentralized energy system provides a home refueling option for drivers who only travel limited distances each day.
\end{abstract}

Keywords: Solar Energy, Hydrogen, Renewable Energy, Distributed Energy, Optimization

\section{INTRODUCTION}

Apart from occasional financial recessions, the long term need for increasing amounts of energy as countries develop will become a major rate limiting step in the growth of the world economy. Primary energy sources of the past including coal, natural gas, and petroleum will be severely challenged in meeting the energy and environmental needs of countries striving to grow and compete in the world marketplace. Coal is faced with severe environmental burdens. Natural gas availability is challenged by its remote distribution around the world, and petroleum is not likely to keep up with demand.

In 2007 the National Petroleum Council (NPC) in the United States published its report entitled: Hard Truths: Facing the Hard Truths about Energy [1]. Projections in the NPC report show that through 2030 supplies of petroleum will flatten or decline even after accounting for existing and known reserves, enhanced oil recovery technologies, and unconventional sources of supply. The NPC report suggests that the difference between increasing world demand and declining supplies represents a gap that can best be filled through expanded exploration and new oil field development. It's our view that such a future energy strategy is highly speculative, politically challenging, and financially risky.

Transportation fuel requirements represent a major percentage of future energy needs. The chart in Figure 1 displays the current US demand for energy by sector. Transportation is the largest sector and is expected to maintain its preeminent position relative to other energy uses out to 2030 [2]. The need for increasing amounts of transportation fuels is also critical in developing economies if they are to have the same opportunities for personal mobility that the developed countries of the world have had during the past century.

General Motors has worked over the last century to meet the personal mobility needs of individual customers. Our intent is to continue to develop combinations of propulsion technology and future fuels that will provide personal mobility options during the next century. It is our expectation that future transportation needs will be met by:

- Improved, more efficient versions of the internal combustion engine operating on cleaner, petroleumbased fuels 
- Continued development of alternative liquid fuels derived from "biomass" including advanced alcohols and renewable diesel fuels

- Development of a variety of hybrid propulsion systems utilizing advanced battery technologies and electrical energy

- Production of renewable hydrogen for use in fuel cell propulsion systems providing pure electric operation and zero emissions.

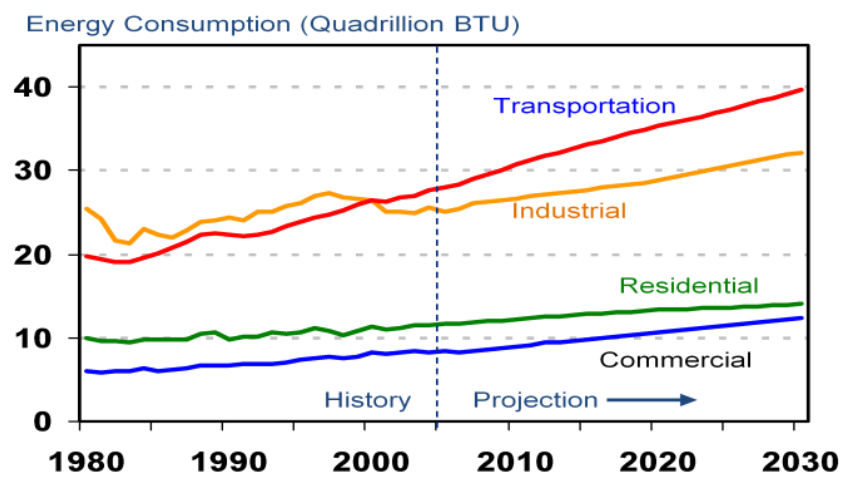

Data source: USDOE/EIA Annual Energy Outlook (2008)

Figure 1. Energy consumption by transportation and other economic sectors out through 2030.

The balance of this paper will focus on the last two elements in this list of future options. This is not to say the first two elements are un-important and will not be pursued. It is merely to provide the focus on technologies that have recently been evaluated within GM that have the potential to meet the very important energy goals of providing: 1) an unending supply, 2) an emissions free source, and 3) an efficient method of collecting renewable energy. More specifically, this paper focuses on the investigation of new, more efficient methods for the capture of solar energy.

The traditional way to capture energy from the sun is to use photovoltaic (PV) cells, modules, and arrays to convert the solar energy into electricity [3]. The DC electricity generated by PV systems is typically converted to $\mathrm{AC}$ and used directly at the source or fed back into the grid to reduce the electricity costs of the PV owner. A more novel approach is to store the solar energy in the form of batteries [4], or hydrogen generated via water electrolysis $[5,6]$.

To date, solar energy has been generated in large centralized plants covering hundreds of acres, such as the 14 MW installation at Nellis Air Force Base (AFB) in Nevada, or in smaller distributed applications of several $\mathrm{kW}$, such as those on individual home roofs [7]. In between these two extremes are PV installations on large commercial building roofs, such as those on manufacturing plants and warehouses. For example, General Motors currently has large solar roof installations on several of its plants; two in California have nearly 1 MW of solar modules, and another in Zaragoza Spain has nearly $12 \mathrm{MW}$ of modules [8]. The latter is the largest solar roof installation in the world to date.

In this report, we will highlight several projects at the General Motors R\&D Center that were designed to investigate solar-driven processes for producing hydrogen from water electrolysis and for charging electrical storage batteries [9-29]. The studies all began with small laboratory scale systems and, in the case of hydrogen, progressed into a solar hydrogen fueler that could produce more than $0.5 \mathrm{~kg}$ of hydrogen from the average solar load in southeastern Michigan. In particular, we will highlight the unique features of the maximum power point (MPP) of PV devices and the ability to directly couple PV arrays with electrolysis and battery charging systems.

\section{EXPERIMENTAL RESULTS AND DISCUSION}

\section{Advantages of the Solar Maximum Power Point and Energy Generation}

Major improvements in solar powered electrolysis and battery charging are needed to increase efficiencies and reduce costs in order to make a solar energy system more practical. One way to improve efficiency is to directly couple the PV electricity generation and the load (an electrolyzer or battery charger) are coupled to produce solar hydrogen or battery charge. The electrical efficiency of the PV system and the conversion efficiency of the electrolysis system in converting electricity to hydrogen fuel energy must be multiplied to find the efficiency of solar hydrogen generation (Equation 1a). Both efficiencies need to be optimized for the maximum system efficiency.

Solar to $\mathrm{H}_{2}$ efficiency $=$ PV efficiency $\mathrm{x}$ Electrolysis efficiency x coupling factor Eq. 1a

Similar statements can be made for a solar battery charging system; only in that case it is simpler because a direct electrical coupling is made between the solar system and the battery modules. Battery charging efficiencies can reach $99 \%$ if the PV system is directly connected to batteries with high conductivity.

Solar to charge efficiency $=$ PV efficiency $\mathrm{x}$ Battery charger efficiency $\mathrm{x}$ coupling factor $\quad$ Eq. $1 \mathrm{~b}$

The efficiency of the solar hydrogen generation system can be optimized by: 1) designing an efficient PV system to capture as much solar energy as possible, 2) utilizing an electrolyzer that maximizes the conversion of electrical energy into the chemical energy contained in hydrogen, and 3) coupling the two systems with the maximum power point (MPP) voltage matched to the voltage 
requirement of the load so that as much of the solar electricity as possible is transferred from the solar collector to the electrolysis system.

An example of a current vs. voltage and power vs. voltage curve for the solar PV array installed at General Motors is shown in Figure 2a. This data was obtained during a cloud-free period near "solar noon". The PV array, solarto-electric efficiency was calculated from Eq. 2:

Solar to electric efficiency $=$ Electric power out $/$ Solar power in

Eq. 2

where:

Solar power in $=$ Solar irradiance $\mathrm{x}$ Array area

Eq. 3

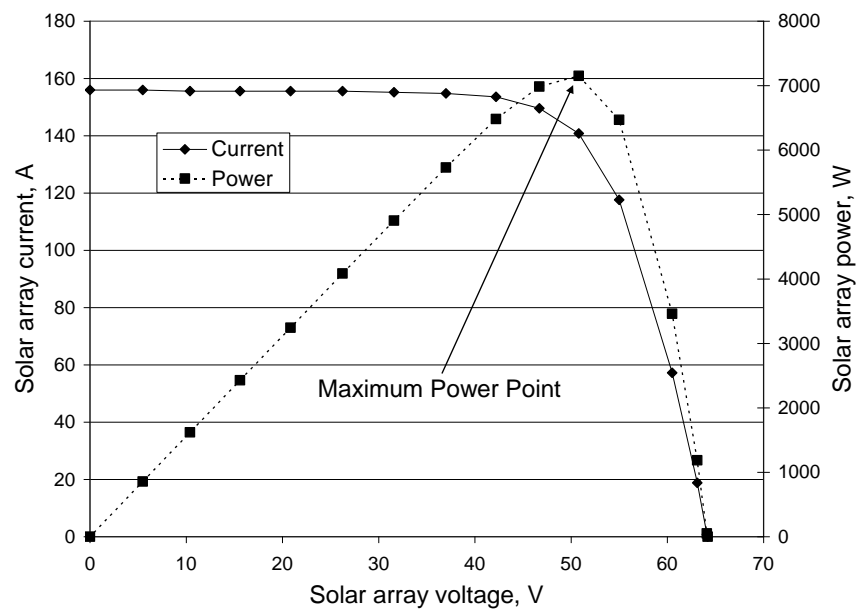

a

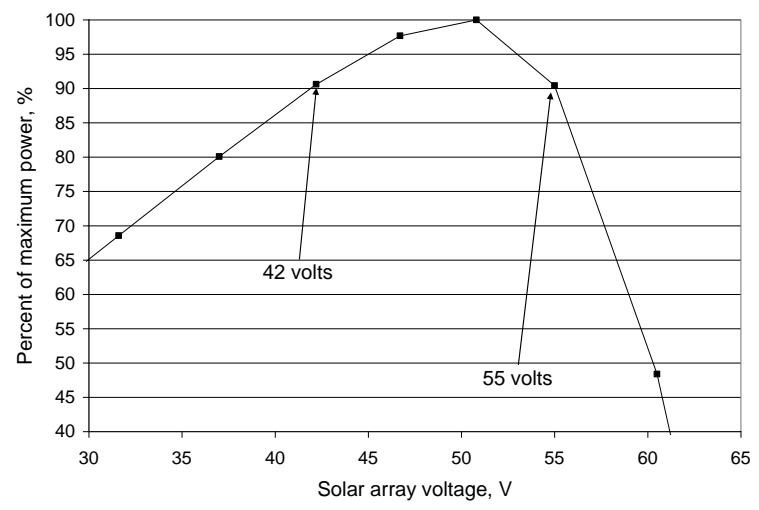

b

Figure 2. Plots of: a) current-voltage and power-voltage curves of the solar PV system, and b) an expansion of the test data, showing the percent of the maximum power near the maximum power point.

The solar photovoltaic array used in this study reaches a voltage (Vmpp), current (Impp), and power (Pmax) of $50.8 \mathrm{~V}, 140.8 \mathrm{~A}$, and $7150 \mathrm{~W}$ respectively at its maximum power point under typical operating conditions $\left(52^{\circ} \mathrm{C}\right.$ array temperature). If we can design an electrolyzer (or other load) that will operate at the same optimum voltage (Vmpp) as the array, the coupling factor in Eq. 1 will approach unity.

The GM solar energy system is matched to the operating point of an electrolyzer or a battery charger without any intervening power conversion devices. The solar arrays contained 40 Sanyo high-efficiency solar modules with a power output of $7150 \mathrm{~W}$ and a total area of $500 \mathrm{ft}^{2}$. The arrays could generate $30 \mathrm{kWh}$ of electricity for hydrogen fuel production or battery charging based on the annual average of 4.2 peak sun hours in Detroit. This amount of energy could produce more than $0.5 \mathrm{~kg}$ per day of hydrogen or an equivalent amount of energy for battery charging.

A closer inspection of the power output of the PV system operating near the MPP is shown in Figure 2b. For voltages from 42 volts to 55 volts, the PV system will produce $90 \%$ of the maximum power for the test conditions, resulting in good coupling between the solar power collecting and power consuming components. Also, if we design a battery module and PV array (which is made up of many PV cells in series) so that the batteries are fully charged just before Vmpp is reached, the batteries will be efficiently charged by the PV system and the charging process will be self regulating due to the rapid fall-off in the PV power to the right of Vmpp.

In essence, we have developed a strategy for optimizing hydrogen generation and battery charging using solar systems in which no charge controllers or power converters are needed. This reduces costs and improves system efficiency. The PV panels were connected directly to the electrolysis unit by designing the solar collectors to provide maximum power at a voltage that would match the fixed operating voltage of the electrolysis cell [10-12, 15, 20, 21]. A slightly different procedure was used for an optimized solar battery charging module by taking advantage of the sharp fall-off in the PV module voltage at voltages above the MPP, resulting in self-regulation of the battery charging. Examples of each of these optimization processes will now be given and the results will be discussed.

\section{Example 1: Solar Maximum Power Point (MPP) Optimized Solar Hydrogen System}

The optimization can be understood by examining the PV current vs. voltage curve from Figure $2 \mathrm{a}$ and the current vs. voltage curve for our experimental high-pressure electrolyzer (Avalence, LLC) [12]. Figure 3 shows the PV and electrolyzer current vs. voltage curves on the same plot.

A picture of the combined PV-ESD (Electrolyzer, Storage, Dispensing) system [12, 14], referred to as the GM Solar Hydrogen Fueler, is shown in Figure 4. A 
second-order polynomial (quadratic) was fit to the electrolyzer current vs. voltage data, and used to extrapolate the curve to where the electrolyzer current and the PV current intersect. The intersection of the two curves occurred at $49.8 \mathrm{~V}$ and $143.3 \mathrm{~A}$. Notice that the intersection for the PV and electrolyzer current vs. voltage curves is very near the PV maximum power point voltage of $50.8 \mathrm{~V}$. For this electrolyzer, which has 24 electrolysis cells in series, the electrolyzer efficiency at $49.8 \mathrm{~V}$, based on the $\mathrm{H}_{2}$ lower heating value, LHV of 1.245 volts, is $60.3 \%(100 \% \times 1.245 \mathrm{~V} \times 24$ cells in series/49.8 V).

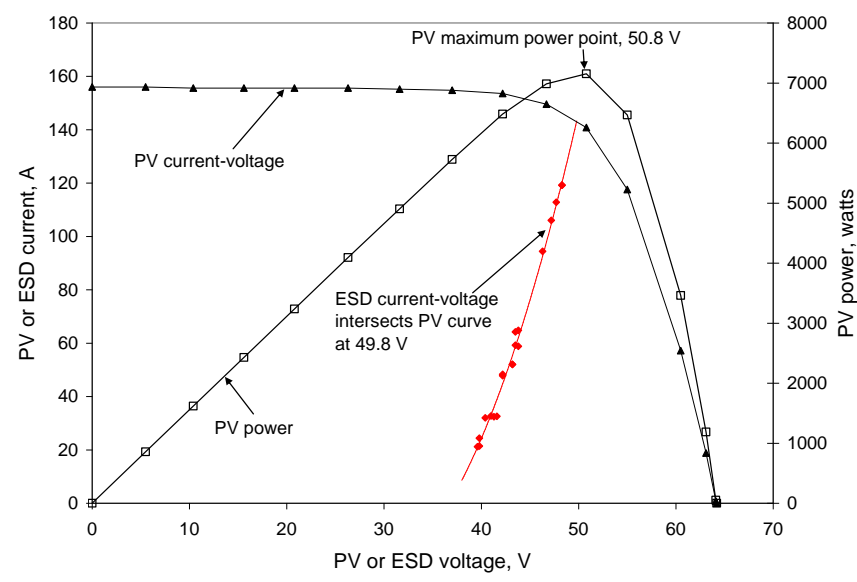

Figure 3. Plot of superimposed current vs. voltage curves for PV and electrolyzer systems, and the power vs. voltage curve for the PV system.

The solar to hydrogen efficiency for a combined PVelectrolyzer system with the operating characteristics shown in Figure 3 is the product of the PV (15.2\%) and electrolyzer efficiencies $(60.3 \%)$ at the intersection of their current vs. voltage curves. This efficiency is approximately $9.2 \%$. The current at this point is $143.3 \mathrm{~A}$. This relatively high current (a result of the electrolysis overvoltage) reduces electrolyzer efficiency because electrolyzer efficiency is inversely proportional to Voper. Nonetheless, the solar to hydrogen system efficiency is approaching $10 \%$ which is higher than that claimed by other PV-electrolysis systems and reported in other studies $(2-6 \%)$.

As a further advantage, our system produces high pressure hydrogen electrolytically with no mechanical compressor at pressures in excess of 6000 psi (415 bar) compared to reported pressures of 300 psi from conventional electrolyzers. At lower PV currents, such as would occur on cloudy days and near sunrise or sunset, the electrolyzer current would be lower, increasing the electrolyzer efficiency, but reducing the hydrogen production because the production rate is proportional to the electrolyzer current. The solar to hydrogen efficiency results and the corresponding solar irradiance for five hours on a sunny day are shown in Figure 5 . The measured efficiencies are very close to the predicted efficiencies based on Eq. 1a [15].

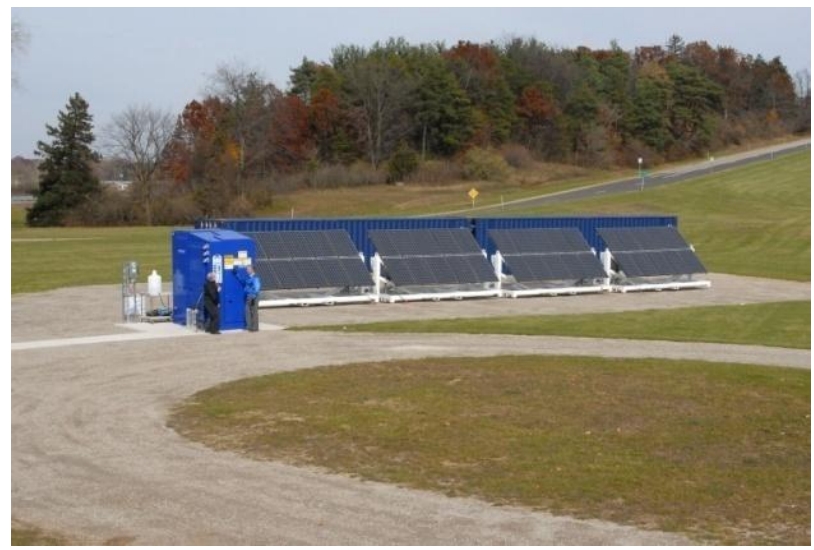

Figure 4. The combined PV-ESD (Electrolyzer, Storage, Dispensing) system, referred to as the GM Solar Hydrogen Fueler at the General Motors Proving Ground, Milford, MI.

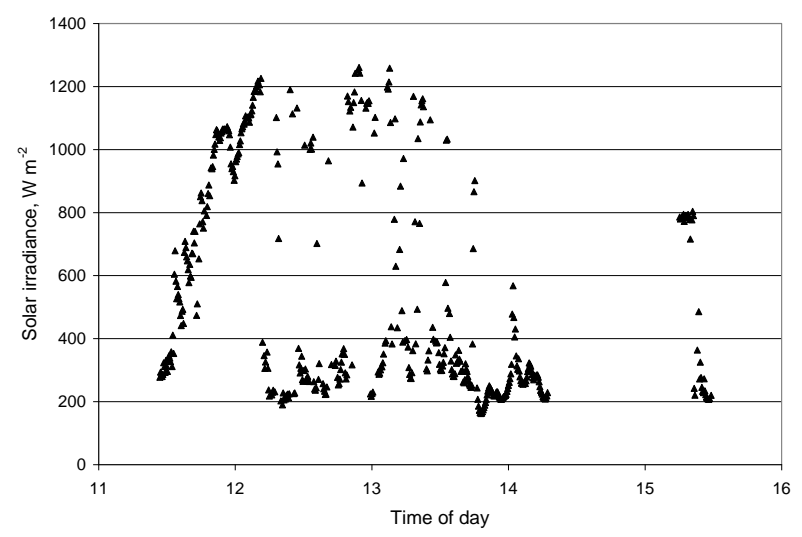

a

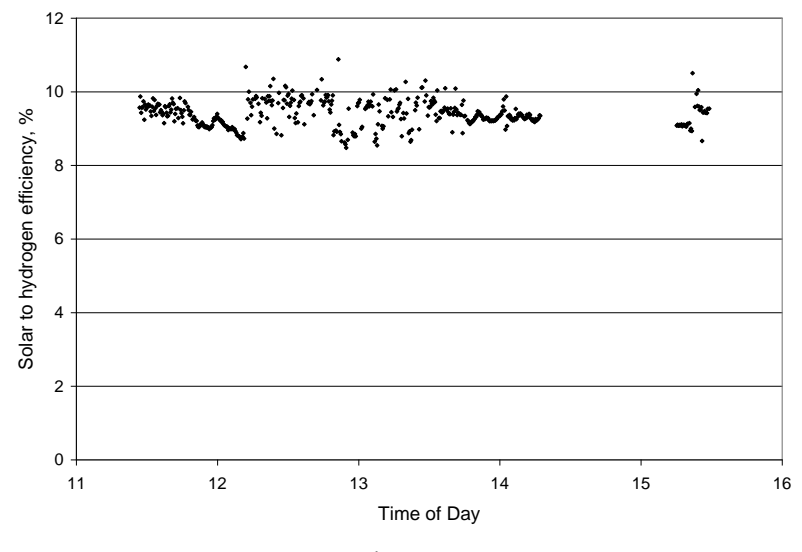

$\mathrm{b}$

Figure 5. Plots of: a) solar irradiance, and b) solar to hydrogen efficiency for the PV-ESD system. 
It is also important to note that the PV and ESD systems remain optimized [10] under a wide range of solar irradiance and temperature conditions. In addition,the solar to hydrogen efficiency remains nearly constant (Figure 5b) even as the solar irradiance rapidly varies by over a factor of six (Figure 5a). As the PV voltage decreases slightly on cloudy days and near sunrise and sunset, the PV MPP voltage also decreases. The ESD operating current is less at lower voltages, so the PV and ESD current-voltage curves intersected at a voltage near the PV MPP to maintain maximum efficiency. In summary, the system design, following the MPP optimization procedure $[11,12,14,15]$ for a direct connection between PV and electrolyzer systems, results in a high PV-electrolyzer system efficiency and maximizes the output of high-pressure hydrogen.

\section{Example 2: MPP Optimized Solar Battery Charging for Plug-in Electric Vehicles}

Hybrid electric vehicles with rechargeable plug-in battery packs are designed to provide commuters with a substitute for fossil fuel-based transportation. Hybrid electric vehicles can be recharged using clean, renewable solar energy generated from photovoltaic (PV) arrays that create the electricity. These considerations led to the development of light, compact Li-ion batteries with three times the energy of a comparable weight lead acid system. Smart controllers are usually used for charging Li-ion batteries because they are subject to heating and can be damaged if overcharged [21, 22, 26-37].

Solar PV charging was evaluated by using the same high efficiency crystalline and amorphous silicon PV modules, shown in Figure 4, that were used for the hydrogen generation experiments. The modules, with a maximum power point of 50-volts, were directly connected to 10 - to 16-cell lithium-ion battery modules during recharging experiments. This PV system was designed to safely charge iron phosphate type batteries to their maximum capacity (2.3 Ah/cell). Safe charging of lithium-ion batteries was assured by choosing a combination of PV MPP voltage and battery module size that provided selfregulation during battery charging [21, 22, 29-35].

The maximum allowable voltage was reached at 4.2 volts/Li-ion cell with a battery capacity at a $100 \%$ state of charge (SOC) value of $2.3 \mathrm{Ah}$. The capacity of each battery module determined by charging and discharging tests in the laboratory, and the measured charging and discharging capacities both confirmed that the charge efficiency and discharge efficiency of the Li-ion batteries are as high as 99\% [29, 30]. Example measurements of current, voltage, and state of charge of a 15-cell battery module during the study are shown in Figure 6. Four battery modules could be charged simultaneously in experiments under clear solar conditions using four identical solar modules mounted in the PV arrays. The tests included multiple comparisons of 10-, 12-, 13-, 14-, 15-, and 16-cell battery modules (Figure 7).

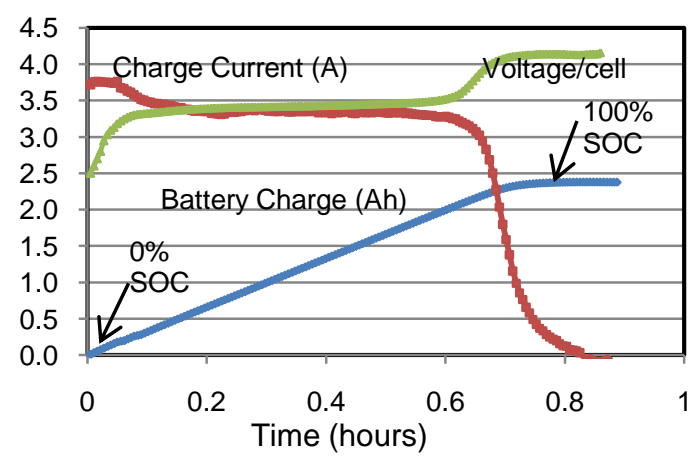

Figure 6. Solar charging of a 15-cell lithium-ion battery module - voltage, current, and battery state of charge.

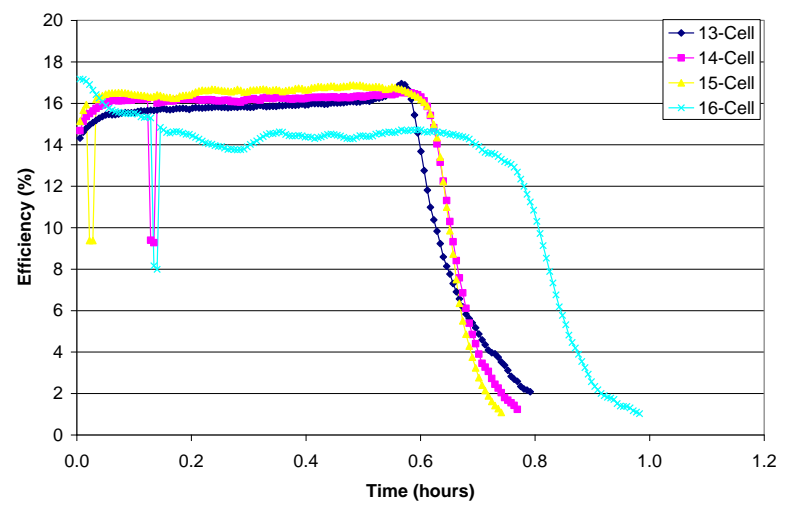

Figure 7. Solar energy to battery charge efficiency comparison.

The efficiency of solar energy to battery charge conversion was also measured. Figure 8 shows the efficiencies for 10- to 16-cell battery modules. The efficiency of each module was determined at $20 \mathrm{~s}$ intervals by an automatic data acquisition system based on Eq. 1b. The efficiency results for each module were averaged and are shown in Figure 8.

The highest solar energy to charge efficiency (17\%) was achieved when the 50.2-V solar PV system is connected with the 15-cell battery module (Figure 7). The effect of matching the maximum power point (MPP) voltage (Vmpp) of the PV system with the charge voltage of the lithium-ion battery module is shown by plotting the solar energy to battery charge efficiency versus the ratio of PV MPP voltage (Vmpp) to charging voltage, where a ratio of 1.0 denotes a perfect match between MPP voltage and charging voltage (Figure 8). 


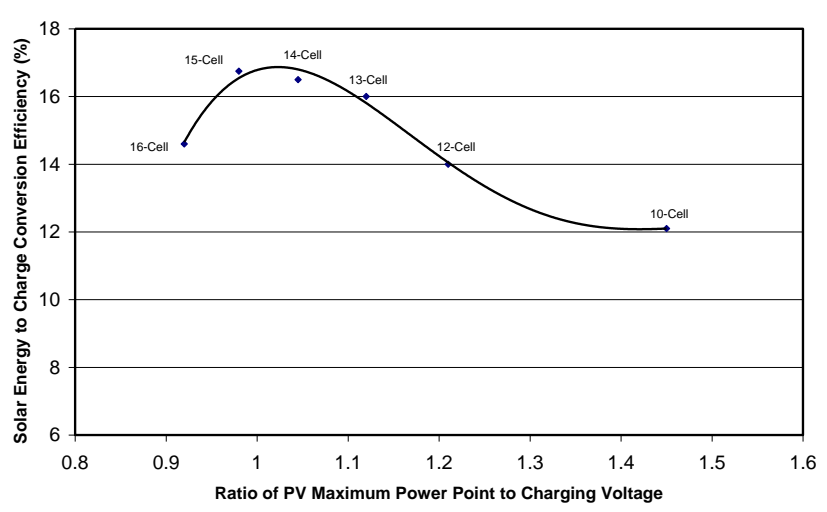

Figure 8. Matching the maximum power point (MPP) voltage of the solar PV system to the charge voltage of lithium-ion battery modules to find the optimum efficiency point at $17 \%$.

The voltage ratio for the 15 -cell battery module with the highest efficiency $(17 \%)$ was 0.97 , meaning that the PV MPP voltage was slightly less than the charging voltage of the battery module. When a 14-cell battery module was charged, the PV voltage to charging voltage ratio was higher (1.03), and the efficiency was slightly less (16\%). When 10-, 12-, 13-, and 16-cell strings were tested, the PV voltage to charging voltage ratio moved farther away from unity indicating that the PV voltage no longer matched the charging voltage demanded by the cells. The charge conversion efficiency curve shows a broad maximum between 14 and 15 battery cells in series equal to the PV voltage to charging voltage ratio of one.

The solar charging efficiency can be optimized by building a PV system with MPP that matches the load, which is the voltage of the battery module during charging (the battery charging voltage). Since the number of battery cells in series is determined for a particular use and operating voltage, the design and charging voltage of the solar charger can also be specified and fixed. Thus, it is necessary to design a solar PV charging system with a MPP voltage as close as possible to the charging voltage [24]. This can be accomplished by designing the PV array with a specific number of solar cells and resulting voltage. Each solar cell of the PV array has a MPP voltage of $0.523 \mathrm{~V}$ at a typical operating temperature of $52{ }^{\circ} \mathrm{C}$. The standard solar module or array with 96 cells in series has a voltage of $50.2 \mathrm{~V}$. Arrays could also be constructed with $\mathrm{N}$ number of cells having $\mathrm{N} \times 0.523 \mathrm{~V}$ to match the voltages of other battery modules designed with different voltages.

A major concern during battery charging comes from the risk of overcharging and the resultant heat generation. In our solar charging experiments, the temperature of the Liion cells never rose more than slightly above ambient, sometimes reaching $30^{\circ} \mathrm{C}$. The mild charging conditions occur because the PV power drops sharply when the system voltage is taken above the MPP as the battery charge approaches its capacity (100\% SOC). This principle is illustrated by Figure 7 , which shows the sudden drop in power and current after the charge voltage rises above the MPP. Because of this drop, our solar charging process has a self-regulating capability, and using the direct connection to solar PV power will significantly reduce the risk of thermal damage to battery systems during charging. Charging current from our solar PV system was limited to $3.47 \mathrm{~A}$ by its inherent maximum power output [26]. Thermal risk can occur from battery discharge during a short circuit when current flow can exceed the maximum cell discharge current of 60 A [26]. This could then lead to melting the connectors between cells or combustion of the cell casings and contents [19, 27, 31]. Another reason why we did not experience significant battery heating was the open construction of the battery modules which left open space between adjacent cells so that heat could escape easily. Battery modules built for use in vehicle battery packs would not have such a construction and might be more subject to a rise in temperature although battery packs can be designed to dissipate heat in other ways. The rapid drop in charging rate shown in Figure 9, due to selfregulation when operating above the MPP, is an important thermal regulation and safety feature of solar charging.

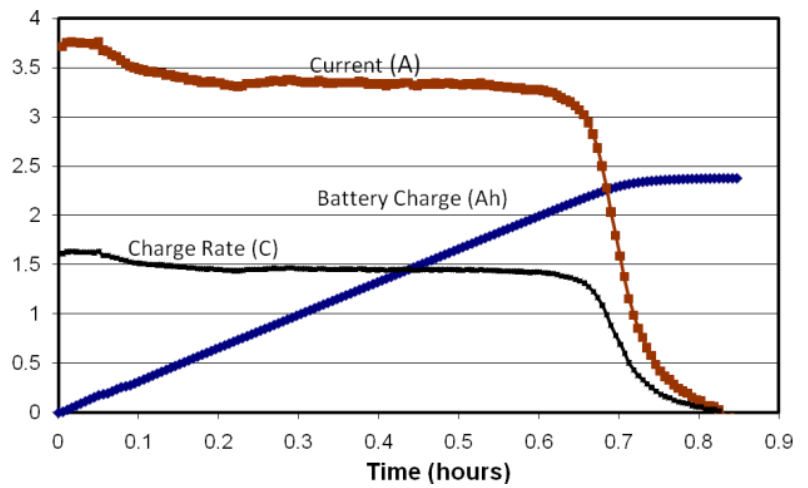

Figure 9. Solar charging of a 15-cell lithium-ion battery module - current, battery charge, and charge rate (C).

The solar energy to battery charge conversion efficiency reached as high as $17 \%$, including a PV system efficiency of $18 \%$ and battery charging efficiency of $99 \%$. By direct connection to the vehicle batteries, a direct DC current battery charger provides maximum efficiency of sun-towheels energy conversion. Solar PV charging can be used at remote locations where grid power is unavailable. It can also be used for home charging of electric vehicles with a relatively inexpensive roof-mounted residential PV array $\left(500 \mathrm{ft}^{2}\right.$ or less). 


\section{Other Potential Improvements in PV Based Energy Systems}

It is important to maximize the efficiency of each individual component of the PV-electrolysis, and PVbattery systems. Other methods to improve the energy capture from the PV array and to increase the electrolyzer and battery charger efficiency [10, 13-29] have been identified as part of this work. The PV energy capture could be improved by utilizing a method to orient PV modules for optimum solar capture on cloudy days [14]. Conventional tracking systems increase the solar energy capture on sunny days when there are no clouds, but on cloudy days such systems can actually reduce the solar energy capture. Orienting the solar modules skyward on cloudy days can improve solar energy capture by over $40 \%$ relative to modules that are oriented toward the obscured sun. It is important to improve the solar energy capture on cloudy days in order to improve the hydrogen yield and battery charging on the days with the lowest output so that system size and cost can be minimized. Another method to improve component efficiencies was to remove heat from the PV system, where higher temperatures reduce efficiency, and add the captured heat to the electrolyzer, where higher temperatures improve efficiency [16]. Finally, a system was designed to capture compression energy in the oxygen waste stream, as well as the hydrogen stream, in a high-pressure electrolyzer $[20,23]$. These potential improvements may contribute to making solar hydrogen production even more efficient and cost effective.

\section{SUMMARY}

Solar energy represents a clean, renewable energy source for production of hydrogen and for charging plug-in electric vehicles. Renewable solar energy eliminates the concerns related to green house gases and other emissions derived from fossil fuel combustion. Given the lack of hydrogen fueling and battery charging infrastructure, a major challenge in the development of hydrogen fuel cell vehicles and hybrid-electric vehicles is to address the need to design efficient systems for home hydrogen fueling and battery charging. This paper contains a proof of concept for this technology in which a major efficiency improvement was achieved by utilizing the unique maximum power point phenomenon of PV devices and matching it to an electrolyzer or battery charger. This design maximizes the coupling efficiency between the PV and load systems. In our study, solar to hydrogen efficiencies approached $10 \%$ and solar to battery charge efficiencies approached $17 \%$. We also proved that sufficient electrical energy can be generated by a $500-\mathrm{ft}^{2}$ PV array on an average sunny day in southeastern Michigan to fuel a FCEV with more than $0.5 \mathrm{~kg}$ of hydrogen or to charge EREVs with $30 \mathrm{kWh}$ of energy. Both energy collection processes can be conducted with optimum efficiency using the same PV array. A self- regulating PV system can also be designed to reduce risks of battery overcharging and potential overheating.

\section{REFERENCES}

[1] Hard Truths - Facing the Hard truths about Energy, A Report of the National Petroleum Council, July 2007.

[2] D. O. E. - Annual Energy Outlook 2008 with Projections to 2030, DOE/EIA-0383, June 2008.

[3] Crabtree G. W, Lewis N. S. "Solar energy conversion," Physics Today, 2007;60: 37-42.

[4] D. O. E. "Energy Storage Research and Development", January, 2009, www1.eere.energy.gov/vehiclesandfuels/pdfs/progra m/2008_energy_storage.pdf.

[5] Turner J. A. "Sustainable hydrogen production" Science, 2004; 305: 972-974.

[6] Turner J. A., Sverdrup G., Mann M. K., Maness P. C., Kropski B., Ghirardi M., Evans R.J., Blake D. "Renewable hydrogen production" International Journal of Energy Research, 2008; 32: 379-407.

[7] SunPower Corporation, $<$ http://www.sunpowercorp.com/For-PowerPlants.aspx>; <http://www.sunpowercorp.com/ForHomes.aspx $>$.

[8] GM web site, <http://www.gm.com/corporate/responsibility/com munity/news/2008/solar_082108.jsp>.

[9] Burns L. D., McCormick J. B., Borroni-Bird C. E. "Vehicle of change" Scientific American, 2002; 287:64-73.

[10] Kelly N. A. and Gibson T. L. "Design and characterization of a robust photoelectrochemical device to generate hydrogen using solar water splitting," International Journal of Hydrogen Energy, 2006; 31; 1658-1673.

[11] Gibson T. L., Kelly N. A. "Optimization of solar powered hydrogen production using photovoltaic electrolysis devices," International Journal of Hydrogen Energy, 2008; 33: 5931-5940.

[12] Kelly N. A., Gibson T. L., Ouwerkerk D. B. “A solar-powered, high-efficiency hydrogen fueling system using high-pressure electrolysis of water: design and initial results," International Journal of Hydrogen Energy, 33, 2747-2764, 2008.

[13] Kelly N. A., Gibson T. L. "Solar energy concentrating reactors for hydrogen production by photoelectrochemical water splitting," International Journal of Hydrogen Energy, 33, 6420-6431, 2008.

[14] Kelly N. A., Gibson T. L. "Improved photovoltaic energy output for cloudy conditions with a solar tracking system," GM Research Publication R\&D11492, October 28, 2008, GM R\&D Center, Warren, MI.

[15] Gibson T. L., Kelly N. A. "Predicting Efficiency of Solar Powered Hydrogen Generation Using Photovoltaic Electrolysis Devices," GM Research 
Publication, May 2009, GM R\&D Center, Warren, MI.

[16] Gibson T. L., Kelly N. A. "Method and Apparatus for Hydrogen Generation," U. S. Patent Publication 20050189234, GM ROI\# GP-304489.

[17] Gibson T. L., Kelly N. A. "System and Sub-Systems for Production and Use of Hydrogen," U. S. Patent Publication 20060065302, GM ROI\# GP-305284.

[18] Gibson T. L., Kelly N. A. "Optimizing Photovoltaic-Electrolyzer Efficiency," U. S. Patent Publication 20070119718, GM ROI\# GP-306592.

[19] Gibson T. L., Kelly N. A. "Apparatus to Reduce the Cost of Renewable Hydrogen Generation by Electrolysis Using Combined Solar and Grid Power," U. S. Patent Publication 20080236647, GM ROI\# GP-309208.

[20] Kelly N. A., Gibson T. L., Ouwerkerk D. B. "Recovering the Compression Energy in Gaseous Hydrogen and Oxygen Generated from HighPressure Water Electrolysis" ROI\# P002809, patent S.N. 12/181,513.

[21] Gibson T. L., Kelly N. A., Sutherland I., Ouwerkerk D. B. "A Solar Battery Charging System and Optional Solar Hydrogen Production System for Vehicle Propulsion," ROI\# P001336, patent S.N. 12/107,857.

[22] Gibson T. L., Kelly N. A., Ouwerkerk D. "Solar Powered Charging Methods and Devices for Lithium-Ion Battery Systems," GM ROI\# P-007144, provisional patent application, S.N. 61/160,460 (filed March 16, 2009).

[23] Kelly N. A., Gibson T. L., Cai M. "An Integrated Solar-Powered High-Pressure Hydrogen, Production and Battery Charging System Solar Powered," GM ROI\# P-008657, provisional patent application, S.N. 61/160,445 (filed March 16, 2009).

[24] Gibson T. L., Kelly N. A. "Photoelectrochemical Device and Electrode" U. S. Patent 7,052,587, May 30, 2006.
[25] Kelly N. A., Gibson T. L "Hydrogen Generator Photovoltaic Electrolysis System" U. S. Patent 7,459,065, December 2, 2008.

[26] Kelly N. A., Gibson T. L. "Solar Photovoltaic Output for Cloudy Conditions with a Solar Tracking System," U. S. Patent Publication 20070084502, GM ROI\# GP-306803.

[27] Kelly N. A., Gibson T. L. "Thermal Optimization of a Solar Powered Electrolyzer System," U. S. Patent Publication 20080236646, GM ROI\# GP-309214.

[28] Kelly N. A., Gibson T. L., Ouwerkerk D. B. "High Pressure Proton Exchange Membrane Based Water Electrolyzer System" ROI\# P001854, S. N. $12 / 251,822$.

[29] Gibson T. L., Kelly N. A. "Solar Photovoltaic Charging of Lithium-Ion Batteries," GM Research Publication R\&D-11744, GM R\&D Center, Warren, MI.

[30] A123 Systems, "Proper operation of A123 Systems high power lithium-ion battery strings," 2008.

[31] General Motors Corp. "Chevy Volt concept sedan specifications," 2007.

[32] Simpson C. "Battery Charging". National Semiconductor, 2007.

[33] Buchmann I. "Improved battery performance with proper battery charging" Cadex, 2001.

[34] GM Corp., Chevrolet Volt EREV - Mule vehicle only electrical safety awareness job aid safe work practices, General Motors University, Course CTIS \#35694, 2008.

[35] Status of the 2-mode hybrid and plug-in hybrid Saturn Vue, 1-08-2009., http://gm-volt.com.

[36] Cadillac Converj review and prices, 2-13-2009, www.Consumerguide.howstuffworks.com.

[37] GM Corp., Volt Brochure, 3-12-2009, https://gmweb.gm.com/gssm/home/EEmessaging/W iki\%20Documents/Volt20\%Brochure\%20Printer\%2 0Spreads final.pdf 